\title{
Social interaction pattern that exist between students who are blind and their sighted peers at University of Education, Winneba
}

\author{
Acheampong, Nana Opoku $\unrhd$ \\ University of Education, Winneba, Ghana (opokunana22@gmail.com) \\ Acheampong, Emmanuel Kwasi \\ University of Education, Winneba, Ghana (ekacheampong@uew.edu.gh) \\ Rockson, Gifty Nana Yaa \\ University of Education, Winneba, Ghana (gnyrockson@uew.edu.gh)
}

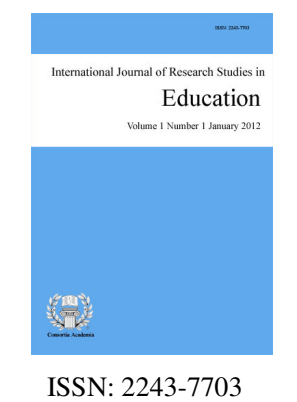

OPEN ACCESS

\section{Abstract}

This case study sought to determine the pattern of social interaction that exists between students who are blind and their sighted peers at the University of Education, Winneba (UEW). The specific objectives were to find out the pattern of friendship between blind and sighted peers, the nature of involvement of students who are blind in cooperative learning activities, and how students who are blind participate in extra-curricular activities in the institution. Twenty-two students who are blind participated in the study, and a semi-structured interview guide was constructed and used for data collection. After a one-on-one, face-to-face interaction with each participant, it was revealed that blind students have a positive pattern of friendship with their sighted peers. They had sighted friends who supported them and with whom they share information and other resources. Also, it was found out that their sighted colleagues involved them in cooperative learning activities, though it was based on "mutual cooperative benefit." However, the study revealed that students who are blind were excluded from some extra-curricular activities due to a lack of sighted colleague's knowledge about their capabilities. The study concluded that the pattern of social interactions between students who are blind and their sighted peers are mostly positive and satisfactory. It was recommended that in organizing intramural sports competitions, the needs of students who are blind should be given recognition to promote their participation in such competitions.

Keywords: blind students; social interaction; social interaction pattern; visual impairment; inclusion; sighted peers 


\section{Social interaction pattern that exist between students who are blind and their sighted peers at University of Education, Winneba}

\section{Introduction}

The social interactions for students who are blind can have enormous influence on their self-esteem and academic prospects. Schools are social spaces and one of the greatest assets of this social space is that it can enhance learning and promote lasting and meaningful interactions with peers (Estell, Jones, Pearl, \& van Acker, 2009). Positive social interactions between students with and without blindness make the students feel recognized, accepted and loved. However, students who are blind sometimes experience unfriendly attitudes from their sighted colleagues because of their conditions, which do not promote their social participation. In discussing the quality education for students who are blind, the level and quality of their social interaction with peers cannot be overlooked. In this study, students who are blind are students who are unable to visually perceive objects or find it difficult to move around without the support of sighted individuals and/or mobility cane. These are students who have registered with the Resource Center for Students with Special Needs (RCSSN) in the University of Education, Winneba for support. The University of Education, Winneba (UEW) is a public university in Ghana that has the mandate of producing teachers with professional competence for teaching at the various levels of education in the country. To promote inclusion at the higher level, the university offers admission to qualified students with special needs which includes students who are visually impaired, hearing impaired, physically challenged, deafblind and those who have cerebral palsy.

Mainstream schools give students with disabilities the opportunity to develop harmonious relationships with their peers (Parvin, 2015) and interactions with friends. The pattern of social interaction of students significantly impacts on the social, emotional and academic performance of the students regardless of the differences that might exist. Social interactions give students opportunities to care about and try to understand others and to respond to the feelings, needs and concerns of their friends. Within the context of social interactions, students with disabilities learn the norms and values of peers and also develop a network of supports (Carter, Hughes, Guth, \& Copeland, 2005). Unfortunately, students who are blind are left out of a lot of socializing activities since they are just put to one side (Kenny, McNeela, \& Shevlin, 2003); hence, they are not able to express peer-related social competences and thus, engage in more solitary play than their sighted peers. In a large-scale study, Koster, Pijl, Nakken, and Houten (2010) found out that students with special needs have fewer interactions with classmates and are less accepted than students without special needs. A study by Rockson (2014) also revealed that, students with visual impairments lacked the support and friendship of their sighted peers.

Students who are blind face challenges in gaining positive social interactions since they are neglected in social activities. Social skills deficits manifested in many individuals who are blind which can, however, lead typically achieving learners to avoid forming friendships with them or exclude them in certain educational and social activities (Estell et al., 2009). In their view, Aviles, Anderson, and Davila, (2006) noted that social exclusion negatively impacts on the academic performance of students with visual impairments since individuals' readiness to learn depends on a healthy socio-emotional development. To promote social interaction and inclusion, Roe (2008) observed that students with visual impairments need to develop awareness of themselves and a range of social skills through a variety of experiences. The author further stated that opportunities to interact with others need to be embedded in everyday whole class activities and also need to be taken as and when they emerge. The study further showed that students with visual impairments interacted and related more with their fellow peers with visual impairments than with their sighted peers. Although some studies have been conduction on the social interaction of students in Ghana and United States (Awini, 2015; Rockson, 2014; George \& Duquette, 2006), few studies have probed that social interaction pattern of students who are blind in higher institutions. The current study therefore seeks to determine the social interaction pattern of students who are blind and their sighted peers at UEW. The research questions of the study were: 
Social interaction pattern that exist between students who are blind and their sighted peers

What pattern of friendship exists between students who are blind and their sighted peers at UEW?

What is the nature of involvement of students who are blind in cooperative learning activities?

$>\quad$ How do students who are blind participation in extracurricular activities at UEW?

\section{Literature review}

Social interaction with peers is also a crucial factor in promoting access and participation in positive life experiences. When students develop positive relationships with peers, they may experience higher self-esteem and motivation in school, which are pre-requisites to academic success (Neary, 2010). Several studies and literature supported the fact that positive social interaction among students with disabilities and their non-disabled peers impact immensely on the academic performance of the former (Aviles et al., 2006; Bromley, 2008; Vacca, Vacca, \& Mraz., 2011; Wilkinson, Soter, \& Murphy, 2010). Hunt, Soto, Maier, Müller and Goetz (2002), found out that the social interaction between pupils with special needs and their classmates seems to be at the core of social participation.

Awini (2015) used the mixed method approach to investigate the nature of social participation of pupils with visual impairments in school activities in selected regular basic schools in Ghana. A phenomenology research design and descriptive survey design were employed. A focus group interview which lasted between 40 to 45 minutes was conducted on 14 pupils while questionnaires were administered to 42 teachers. The results revealed that the sighted peers of the pupils with visual impairments interacted with them, played regularly with them, had fun together, worked with them during group assignments, and were never treated harshly by their sighted peers. The study concluded that there was some fair level of social participation of students with visual impairments and blindness in activities in the schools.

Quite consistent with the findings of Awini's study is that George and Duquette (2006) which employed the qualitative approach to explore the psychosocial experiences of a student with low vision. The case study used a semi-structured interview, classroom observation and a review of student's school file/documents for data collection. The major findings of this study were that the psychosocial development of students with low vision may not always be compromised by limitations of or perceptions of visual impairment and that these students may not, inevitably, have difficulty with peer relations. Eric perceived himself as a socially accepted member of his class who was treated as an equal by teachers and peers. The current study involves 22 students who are blind and does not include students with low vision.

\subsection{Friendship pattern of students with disabilities}

Friendship, according to Gordon, Feldman, and Chiriboga (2005), is very essential in the lives of many people. It is also an important factor in the social, cognitive and emotional development of students (Schneider, 2000; Tipton, 2011) including students with disabilities. Social participation of students with disabilities is enhanced through friendship, which has multiple meanings and varies across cultures, though with some common dimensions (Keller, 2004). Friends are defined as people who spend time together, participate in more intense social activities together, and show higher rates of cooperation (Bowker, 2004). According to Freeman and Kasari (1998), "friendship is a social relationship based on interactions that are reciprocal, stable and serve the functions of intimacy, companionship, emotional support, and affection" (p. 343). Friendship can also be seen as a kind of social relationship between people that promote mutual feeling of trust, affection and support. Friendship provides the youth with the opportunity to learn about peer norms, values, accepted social behaviours and develop self-determination and other valuable life skills (Brown \& Klute, 2003; Carter, Swedeen, \& Kurkowski, 2008; Gifford-Smith \& Brownell, 2003).

Studies have found out that within the group of students with disabilities, students identified with sensory disorders find it particularly difficult to build relationships with typical peers and are at risk of becoming isolated in the classroom (Chamberlain, Kasari, \& Rotheram-Fuller, 2007). Robinson and Truscott (2013) noted that making and maintaining friendships is primary themes that emerge as critical to a sense of belonging in school for students with disabilities. A survey conducted in Norway also found that students with disabilities and those 
with behavior problems had a considerably more difficult time finding and keeping friends (Frostad \& Pijl, 2007).

Acceptance of students with disabilities is key to the creation and sustenance of a healthy friendship. The acceptance of students in the peer group is of relevance for both their social and academic development (Schaffer, 1996). However, students with disabilities seem more vulnerable to being isolated (Pijl \& Frostad, 2010) and less accepted in inclusive classrooms. For instance, Pijl, Frostad, and Flem (2008) found that, up to $25 \%$ of students with disabilities were not accepted, did not have any friend and did not participate in a subgroup in class, while only $8 \%$ of their typical peers went through similar experiences. This was consistent with the findings of a previous study by Frostad and Pijl in 2007 that students with special needs were often less popular than their classmates and had fewer friends, even in inclusive settings. This seems to affirm the notion that although researchers have recognized the social benefits of inclusion education, inclusion does not automatically lead to more social contact and friendships between students with and without disabilities (Scheepstra, Nakken, \& Pijl, 1999). For students with visual impairments, making friends is a daunting task, even though friendships create contexts in which basic social skills are acquired and extended (Dunn, 2004).

Majority of studies on friendship of students with disabilities have been on children and adolescents (Awini, 2015; Gordon, Feldman, \& Chiriboga, 2005). Ciairano, Rabaglietti, Rogerro, Bonino, and Beyers (2007) noted that the quality of friendship is one of the most important aspects of friendship development in adolescence. In an ethnographic study by Matheson, Olsen and Weisner (2007), 27 Euro American teenagers with developmental disabilities were asked to describe their friendships through a semi-structured interview. The study engaged six field workers who visited and lived with a maximum of 7 participants assigned to them. They were to record their observations of the assigned participants and their self-described friends and peers. The participants responded to a semi-structured interview about different aspects of their lives including friendship. Matheson et al. coded the interviews for 11 domains of friendship drawn from the literature on typically developing children: similarity, proximity, transcending context, companionship, reciprocity, mutuality, help/support, conflict management, stability, trust/loyalty, and intimacy/disclosure.

Matheson et al. found companionship as very important for the teens among other popular themes such as similarity, and stability/proximity. On the other hand, intimacy/disclosure, support, reciprocity, and trust/loyalty were less frequently discussed. The ethnographic observations also indicated that the large majority of the teens in the study did have friendships and were socially engaged in ways that they themselves found satisfying. They also had positive and stable friendship with their peers with developmental disabilities than with typically developing peers.

In another qualitative study, Lifshitz, Hen, and Weise (2007) focused on investigating the self-concept, quality of friendship and adjustment to blindness among adolescents with visual impairments. The participants included 40 sighted adolescents and 40 adolescents with visual impairments selected from public schools and residential school in equal numbers. The quality of friendship scale was administered to gather data on the quality of friendship aspect of the study. It was evident that both groups of visually impaired adolescents responded similarly to the instrument in four of six subscales while the sighted adolescents scored significantly higher on the other two subscales which are spending leisure time together and confrontation and betrayal. These findings were consistent with that of Sacks and Wolffe's (1998) who also found the quality of friendships and social interactions to be low among adolescents with visual impairments due to their difficulty to acquire social skills and inability to use nonverbal communication. This current study is set apart from that of Matheson et al. (2007) and Lifshitz et al. (2007) because it focuses on adult students who are blind in a higher institution.

\subsection{Cooperative learning with sighted peers}

Gillies (2004) explained cooperative group learning as a small number of students working together on a common task through sharing of resources, encouraging each other's efforts and assisting each other in 
Social interaction pattern that exist between students who are blind and their sighted peers

completing the task. Recognizing that students can be the best teachers, small group sessions can be planned to work on skills that students need to develop, consequently, providing the opportunity for students to engage in positive social interaction with peers (Roe, 2008). Students benefit in many ways when engaged in cooperative/group learning activities. Cooperative learning can be used to promote the acceptance, self-esteem, social skills and positive interaction of students (D'Allura, 2002). Slavin (2009) also concluded that cooperative learning strategies promote social interaction in learning and helps students to feed knowledge to one another. Students who perform a task in group learn to perform that task independently in future because of the knowledge and skills learnt in performing the group task. Vigotsky (1962) quoted in Schneider (2000) affirmed this view saying that what a child can do in cooperation today, he can do alone tomorrow.

In spite of the many benefits of learning in groups, students with disabilities, including students who are blind, are less likely to be involved in group activities. Pijl and Scheepstra (1996) reported that students with blindness attending a mainstream school in Holland were the least likely to be involved in small group work in the classroom. The authors further reported that, whereas the nature of their interactions was similar to that of their typical classmates, the students with blindness took less initiative for interaction.

A study conducted by Boruvkova and Emanovsky (2016), in Czech Republic involving 207 learners of first, second, and third grades of lower secondary schools was to find out if cooperative learning methods could help to integrate isolated learners into the class. Pre-test-post-test design was employed for the study. Standardized sociometric questionnaire B-3 was used to determine the number of isolated learners before and after using the cooperative learning methods. The number of isolated learners (sociometric results) obtained during the use of the classical frontal learning without any cooperative learning method was compared with the number of isolated learners after a five-month application of cooperative learning method. The results revealed that the number of isolated learners within the frontal teaching and cooperative learning were statistically significantly different. The number of isolate learners within the classical frontal teaching was higher than after using the cooperative learning method. The study concluded that cooperative learning is very useful in helping the marginalized students to be incorporated into their team and enjoy the benefits of learning in a group. The current study differs from that of Boruvkova and Emanovsky because the current study employed interview as the instrument for data collection.

Rockson (2014) also employed the descriptive survey design in exploring the strategies teachers use to promote interaction among students with visual impairments and their sighted peers in selected integrated senior high schools in Ghana. Using purposive and random sampling techniques, 75 participants were selected for the study which included teachers, students with visual impairments and regular education students. Among the findings of the study was that teachers used group work (peer tutoring) as a strategy to promote social interaction among the two categories of students in the schools. The studies that have been reviewed seem to emphasize the importance of cooperative learning in promoting social interaction among students. This current study sought to find out, among others, the extent of involvement of students who are blind in cooperative learning activities.

\subsection{Participation in extra-curricular activities among students with visual impairments}

According to Massoni (2011), extra-curricular activities are activities that students participate in that do not fall into the realm of normal curriculum of schools and they are in many forms such as sports, clubs, hall week celebrations, religious fellowships and drama. Massoni further indicated that "extracurricular activities are a part of students' everyday life. They play important roles in student's lives. They have positive effects on student's lives by improving behavior, school performance, school completion, positive aspects to make successful adults, and social aspects (p. 86).

Several studies have found out that students' participation in extra-curricular activities have the potential to influence positive gains in social relationships (Fletcher, Nickerson \& Wright, 2003; Howie, Lukacs, Pastor, Reuben, \& Mendola, 2010; Siperstein, Glick, \& Parker, 2009). Fredricks and Eccles (2006) found that students 
who participated in a greater number of extra-curricular activity contexts demonstrated higher levels of academic adjustment, psychological adjustment, and civic engagement, and lower rates of involvement in risk behaviors (including drug and alcohol usage) during adolescence. Extra-curricular activities, such as sports, are good avenues for students to develop and maintain friendships. Movahedi, Mojtahedi, and Farazyani (2011) compared the social skills of Iranian teenage students with visual impairments who were athletes and non-athletes using the Social Maturity Scale. The authors examined 51 athletes who were visually impaired and 56 non-athletes who were visually impaired. The results proved the notion that participation in sports resulted in better improvements in socialization. They recommended that officials and students should encourage sports participation of students with visual impairments.

In spite of the documented benefits of extra-curricular activities, students with disabilities, including students with visual impairments, are generally less involved in recreational activities outside of school time (Solish, Perry, \& Minnes, 2010), consequently, students with visual impairments have less opportunities for interactions with sighted peers (Gore, 2015). In a small-scale qualitative study Shevlin, Kenny, and McNeela (2002) reported on the experiences of students with disabilities where some of those students were left to watch physical education rather than participate and were not permitted to go on school trips. The participants in the study further expressed that they felt excluded and even more aware of their differences when they were not permitted to participate in such extra-curricular activities. Kearney (2009) also found among others that students with disabilities experience access difficulties associated with enrolment at school and participation in curriculum and extra-curriculum activities.

Gibbons (2013) conducted a mixed-method study to explore the participation of high school students with disabilities in school-based extra-curricular activities using survey questionnaire and interview as data collection instruments. Seventy-one high school students, including students with disabilities, and 150 youth leaders/coaches were the participants for the study. In their interviews, student participants discussed societal participation barriers enacted by their school peers as inhibiting factors to participation. The students further expressed that participation was based on their interest and were facilitated in or discouraged from participating by parents based on established boundaries and roles. The coaches and leaders data also indicated that leaders recognized that students encountered barriers to their participation, but often did not understand the ways in which their perceptions of disability shaped some of the barriers students with disabilities encountered. The current study, however, did not include youth leader/coaches as participants.

Contrary to the findings of the above studies, a student with low vision and the principal participant in a single-case study conducted in Canada was found to be engaged in a variety of sporting activities, both at school and in the community. In spite of occasional attempts by peers to exclude him in games because he was unable to play competitively, the participant remained motivated and continued to play intramural sports at school as well as sports that were organized in the community. The student's parents also encouraged their child to participate in sports by enrolling him in numerous activities outside school, such as hockey, wrestling and skiing) which supported his physical and social development (George \& Duquette, 2006). The gap in George and Duquette to be filled by the current study is that, these researchers concentrated only on the student's participation in sports but did not find out the nature of the students' friendship and experiences in cooperative activities with the sighted peers that the current study set out to do.

\section{Methods and materials}

\subsection{Research design and participants}

This study adopted a descriptive case study design. Descriptive case study was used because it enables researchers to describe a phenomenon and the real-life context in which it occurs (Yin, 2003). The participants for the study were 22 students who are blind pursuing a 4-year bachelor's degree programmes in Departments of 
Social interaction pattern that exist between students who are blind and their sighted peers

Special Education, Social Studies Education, Political Science Education and English Education. They comprised of 13 males and 9 female students between the ages of 21 and 41. First-year students who are blind were not included in the study because the study focused on only students who had more than one-year learning experience in the university. The participants were purposively sampled for the study.

\subsection{Instrumentation}

A semi-structured interview guide was used to elicit data from the participants for the study. The researchers chose one-on-one, face-to-face interviews for data collection because it is ideal for interviewing participants who are not hesitant to speak, who are articulate, and who can share ideas comfortably (Creswell, 2012). According to Creswell, one-on-one interview is a process of data collection in which the researcher asks questions to and records answers from only one participant in the study at a time. The interview questions were guided by the themes that emerged in the objective of the study, namely: friendship pattern, nature of involvement in cooperative learning activities and participation in extracurricular activities.

\subsection{Procedure for data collection}

Two of the researchers were tasked with the collection of data. The researchers began the data collection by seeking permission from the university librarian to use the recording room for the interviews through an introductory letter and helping participants to fill a consent form. Participants were assured by the researchers of their anonymity and confidentiality of information to be gathered in the consent form and dates scheduled with them for the interviews. In view of the busy schedules of participants, appointments to meet each participant for the interview were scheduled in the evenings and on weekends where participants had free time to spare. Two of the researchers interviewed 11 participants each. It took the researchers 12 days to gather data from the participants. Each interview session lasted between 13 to 19 minutes. The interviews were conducted between $13^{\text {th }}$ September 2019 and $24^{\text {th }}$ September 2019.

Participants were given the opportunity to express their feelings and experiences without undue pressure on them. The interviews were tape-recorded with the permission of participants and transcribed for analysis. The recorded responses were played back to each participant for confirmation immediately after the interview session.

\subsection{Validity}

Vanderstoep and Johnston (2009) explained validity as the ability of an instrument to measure what it is intended to measure. Content validity was adopted to ensure the validity of the interview items. In this regard, the semi-structured interview items were developed to cover the key themes raised in the research questions. Macmillan and Schumacher (2001) indicated that participants' in-depth interviews need to be conducted in natural settings to reflect the reality of life experiences more accurately than do laboratory settings. In this study, however, the focused group interviews were conducted in the natural setting of the participants, which is the resource centre for students with special needs in the university where they mostly visit for support or spend some time of the day reading accessible learning materials.

\subsection{Reliability}

According to Creswell (2012), reliability means that scores from an instrument are stable and consistent. Creswell further indicated that scores should be nearly the same when researchers administer the instrument multiple times at different times. To ensure reliability of the interview items, the items were peer-reviewed by the researchers. Again, a pre-test interview was conducted on three students with visual impairment to detect ambiguities and weaknesses in the items for correction and modification so as to improve the internal consistency of the instrument. The items were further presented to another professional in the field of the education of the visually impaired for suggestions that were subsequently effected. 
3.6 Data analysis

The data gathered were transcribed for analysis. Content analysis was employed. In this study, the researchers engaged the transcribed responses of the respondents and inductively coded the responses for categorization. The coding and categorization aided the researcher to identify the themes that emerged. Verbatim expressions of the students were used in reporting the data where necessary.

\section{Result and discussions}

\subsection{What pattern of friendship exists between students who are blind and their sighted peers at UEW?}

Research question one sought to find out the pattern of friendship that exists between students who are blind and their sighted colleagues in the institution. The results revealed that majority of the students had many friends from different departments and faculties in the university with at least one sighted student being an intimate friend. The participants indicated this in the following responses:

It is easy to make friends with the sighted. Both male and female sighted students usually approach me nicely in class and at social grounds to ask for my name. Some even request to be friends with me. I have a lot of friends who help me in diverse ways (Student 2).

Another student also commented this way:

I have many friends both in my department and in other departments who I consult for help when I have problems in my course work (Student 1).

One student also said that:

I don't have any problem making friends with the sighted. It is so easy. Sometimes when you get to class and you need assistance you may not even say it, they themselves will come and assist you. Through that I take their contacts and other information about them so that when I need their assistance I can call them to find out if they can offer me some specific assistance (Student 8).

Another student had this to say:

It is easy for me to make friends with the sighted. I have a good number of friends in the university. In fact, I can say most students with visual impairments have many sighted friends and they help us in our learning (Student 14).

Another student added this:

Most of the sighted students are friendly to us. Only a few are unfriendly to us but we understand because of our knowledge about individual differences. Personally, I have many friends in the university (Student 5).

Commenting on intimate friendship, two participants indicated:

Even though some sighted colleagues support us to a greater extent, some of them cannot be trusted. It is only a few that are trustworthy. I have two sighted friends I trust and share most important information with. You will always see me with one or both of them either learning or eating together (Student 9).

It is not all sighted students you can share your secrets with. You have to study them and know those you can be intimate with and who can keep your secrets. We have made few intimate 
friends and those we play with and can assist us in other ways (Student 17).

One student also said this:

I don't have trust in most of the sighted friends except one whom I met last semester who is in the Department of Graphic Design. Because of me, he arranged to stay in the same room with me so that he can help me. He is kind and I trust him very much. We share vital information and also learn together (Student 20).

Another student remarked that:

As for me, I have only one intimate friend among the sighted. Even with her, I had to try her with some information first before I could trust her because most of them are not secretive (Student 18).

The analysis of the comments revealed that the students' intimate friends also supported them and shared information and other resources with them. It is clear from the comments of the students that the pattern of friendship with their sighted colleagues is positive.

The findings on the friendship pattern of the participants support studies by Awini (2015) and Matheson et. al. (2007) who reported that majority of students with disabilities did have friends who were not disabled and the sighted peers of the students with visual impairments interacted with them and were not treated harshly by the sighted. However, these findings were inconsistent with the findings of Frostad and Pijl, (2007), Pijl, Frostad, and Flem (2008) and Koster, Pijl, Nakken, and Houten (2010) who found that students with disabilities had fewer friends without disabilities and were less accepted in the mainstreamed schools. Rockson (2014) also found in her study that, students with visual impairments lacked support and friendship from their sighted peers. Rocksons' study further showed that students with visual impairments interacted and related more with their fellow peers with visual impairments than with their sighted peers. Thus, the findings of Rockson (2014) do not manifest in the current study, not even from a minority of the students view point.

\subsection{What is the nature of involvement of students who are blind in cooperative learning activities?}

Research question two was to examine the nature of involvement of students who are blind in cooperative learning activities. The findings indicated that generally students who are blind in the university were involved in cooperative and/or group interactions. Although one of the participants expressed the unwillingness of some sighted students to involve them in cooperative activities, majority indicated that the sighted students were prepared to engage them in cooperative interactions. Some students revealed that some sighted students tried very much to ensure their participation in group tasks which promote their academic performance. One participant expressed his view this way:

The sighted colleagues in my department have been involving us in group works. They always call to inform us on the time and place of meeting when we have a group task to execute. Even if we may not have anything much to bring on board, they want us to be there so that we can also listen to whatever they will say and learn together. I must say I learn much from such interactions so I don't miss such opportunities (Student 3).

Another participant remarked that:

In some of the groups I find myself with the sighted, they involve me. They call me and ask me to write my points on the question given so that we can discuss them together with what they also have. When they get to know that you have some good information to share, they constantly call on you when there is a group assignment to do. In level 100 we formed a study group and they 
always came for me to discussion because when we meet I play the lecture notes I recorded in class for them to hear (Student 6).

One participant had this to say:

When we are given assignment to perform in groups, the sighted in my class always make sure we have groups so that we can also participate in the group work (Student 15).

Another participant added,

The sighted come for me from my hostel for group discussions when they realize I am not coming early. Even when I am not around and they do the work, they bring a copy to me and discuss the content with me. But I always try to be there because I benefit more from that (Student 4).

However, one participant revealed that he was not involved in group work. The participant indicated the unwillingness of sighted students to ensure their presence in doing group work and discussions. The participant noted:

We are neglected from participating in group work. The sighted will not get close to you to take your number so that when it is time for discussion they will call you. When you ask them to tell you when they are going to do the work too they will not do it. They will go and do it and just add your name and index number. They always assume we don't have anything to share. It makes me feel bad because if that question appears in exams I may not be able to do it (Student 17).

The findings indicated that the participants believed the sighted were prepared to involve them in cooperative activities because of what their sighted colleagues benefited from them; however, the students stated their desire to always be at group meetings because of what they also gained from it. This is what could be termed as 'mutual cooperative benefit'. Findings are inconsistent with the findings of Pijl and Scheepstra (1996) who reported that students with visual impairments attending mainstreamed schools were least likely to be involved in small group work in and outside of the classroom.

\subsection{How do students who are blind participation in extracurricular activities at UEW?}

On the issue of involvement in extra-curricular activities, the participants revealed that they were not sufficiently involved in sports and hall week celebration activities in the university. The participants were of the view that sighted students do not know much about their abilities and how to choose activities or adapt equipment to promote their participation in extra-curricular activities. Participants revealed that sports equipment were not adapted to promote their participation in intramural sports. Even though one of the participants indicated that few of them were given the opportunity to participate in some events in the inter university games occasionally, they believe that the equipment were not suitably adapted to promote their competitiveness and participation in other sporting activities. The students felt they were left out of many events which they could participate in. The following are expressions of some participants:

For participation in inter-hall sporting and hall week celebration activities, it is sad to note that we are not much involved which is bad. We have complained about it to our hall executives severally but they do not listen to us. They don't know what we can do and they do not seek our views regarding the organization of these extra-curricular activities. They think we cannot do anything so they do not worry themselves to involve us (Student 7).

Our participation in hall week celebrations is not good at all. Even when you avail yourself to participate in any of the activities like float, the sighted are not willing to support you because they think holding your hand and moving with you will be a burden of him or her. Some even frighten us that floats are dangerous (Student 12). 
One student remarked that:

In fact, for sports we don't get the support we need to be involved in it. The sighted executives will not tell you about any upcoming inter hall games or week celebration and find out what you can participate in (Student 8).

Another student also said this:

Our experiences regarding participation in sporting activities and hall week celebrations are not good at all. The sighted do not engage us in any of the events and activities during these periods. Last time when I confronted one of the hall executive about our non-involvement, she told me that they are afraid we will hurt ourselves participating in events like float and cooking competition (Student 6).

Another student added:

They don't involve us in the inter-halls sporting activities because they don't have the equipment. You know for us we need specialized equipment. They also don't want to buy the equipment for us because they say it is costly. Even for the university games we didn't really have all the equipment; they were not well adapted for us. So we had the chance to participate in only one game which is goal ball (Student 11).

However, the students revealed that they enjoy their involvement in religious activities in the university. One student noted:

As for church service there are church members who come for me to go to church. At church we sit together with the sighted and we are also given the opportunity to join the instrumentalists or choir if you know how to sing or play any instruments (Student 9).

Three students commented this way:

Our participation in religious activities is good. Sometimes when we are going out for a programme, the sighted come for us so that we go together. We the Muslims have been going to the mosque regularly and even one of our visually impaired colleagues is now the Ghana Muslim Students Associations' Deputy Secretary (Student 15)

With regards to church service it is good for me. When it is time for church I have some friends who usually call and come for me to go to church. I am involved in the church activities such as dancing, singing and more. I have fun at church very much (Student 22).

As for church service I enjoy my participation in activities like Bible studies and singing. It is interdenominational church service that I don't usually attend because I don't enjoy the participation I enjoy at my mother church (Student 1).

Another student had this to say:

I must say I appreciate my involvement in church programmes. I am part of the singing group and the sighted students come for me to rehearsals and programmes outside campus. Our church has even appointed some sighted colleagues who see to our welfare and participation in church activities (Student 20).

Analyzing the comments, it was clear that the sighted students lacked knowledge about the capabilities of students who are blind which largely resulted in their exclusion from some extra-curricular activities. It could be deduced from the responses that participants were displeased with their exclusion in hall and sporting activities in the university. It could also be seen that some participants have severally registered their displeasure to hall 
executives and university authorities but to no avail. On the contrary, the participants were satisfied with their involvement in religious activities such as church services. They indicated their recognition by the sighted peers in religious activities to the extent that they are given the opportunity to participate in various activities of the religious groups and in some cases serve as leaders of the group.

The findings support that of Schedlin, Lieberman, Houston- Wilso and Cruz (2012) and Shevlin, Kenny and McNeela (2002) who reported that students with disabilities were left to watch physical education rather than participate and were not permitted to go on school trips. Shevlin et al. (2002) further noted that participants felt excluded and even more aware of their differences when they were not permitted to participate in such extra-curricular activities. Schedlin, et al., (2012) found that modifications to instruction, the environment and equipment were not made to allow participants to successfully participate in physical activities. Results of the study by Schedlin, et al. further revealed that both participants in the study participated in physical activities at a lower rate that their sighted peers. Contrary to the findings of the above studies, a student with low vision and the principal participant in a single-case study conducted in Canada was found to be engaged in a variety of sporting activities both at school and in the community (George \& Duquette, 2006). It is evident from the discussions that, there existed some levels of social interaction with the sighted in the university but not at a satisfactory level as indicated by the participants.

The findings of the study were supported by Tinto's (1975) model of students' retention or departure. Tinto indicated that social interaction is dependent on the student's ability to become involved in the university community as well as connect to the peer and engage in the social life of the institution. This implies that when students with visual impairments are exposed to challenges in their participation, they are likely to depart from the activities of the university or even quit. Tinto postulated that whereas academic interaction is a requirement for students' retention, social integration is not. However, both academic and social interactions have potential influences on student involvement and retention in a university.

\section{Conclusions and implications for practice}

The study revealed that the students who are blind were accepted and supported by their sighted peers in the university which created friendship among them, yet the students had fewer intimate friends due to lack of trust in their sighted colleagues. The study also revealed that sighted students involved the students in group learning activities. The sighted were prepared to involve them in group works largely because of what they also benefited from students who are blind. It should however be noted that, one of the participants stated that the sighted were not prepared in some cases to involve them in group activities. Further analysis of the data revealed that the students were not involved in extra-curricular activities in the university. Participants were excluded from participating in sporting and hall week celebration activities because the non-disabled students probably lacked knowledge of their capabilities. The study underscores the need for the university sports and games committee to ensure that the Students Representative Council Sports executives and Hall of Residence Sports executives procure adapted sports equipment for students who are blind in the institution. Surprisingly, the participants were satisfied with their involvement in religious activities such as denominational and interdenominational church services.

In view of these findings, it was concluded that the pattern of social interactions between students who are blind and their sighted peers is largely positive and satisfactory. The study, therefore, recommend that in organizing intramural sports competitions, the needs of students who are blind should be give recognition to promote their participation in such competitions. It was also suggested that lecturers should provide learning activities that promote greater cooperation among students.

Acknowledgement - We wish to express our heartfelt gratitude to the participants who devoted their resources to participate in the study. We are also grateful to the staff of the Department of Special Education for their support. 


\section{References}

Aviles, A. M., Anderson, T. R., \& Davila, E. R. (2006). Child and adolescent social-emotional development within the context of school. Child and Adolescent Mental Health, 11(1), 32-9. https://doi.org/10.1111/j.1475-3588.2005.00365.x

Awini, A. (2015). Social participation of pupils with visual impairment in school activities in selected regular basic schools in Ghana [Unpublished doctoral dissertation]. University of Education, Winneba, Ghana.

Bogdan, R. C., \& Biklen, S. K. (2007). Qualitative research in education: An introduction to theory and methods (5th ed.). Boston: Pearson Education, Inc.

Boruvkova, R., \& Emanovsky, P. (2016). Small group learning method and their effect on learners' relationships. Problems of Education in the 21st Century, 70, 45-58.

Bowker, A. (2004). Predicting friendship stability during early adolescence. Journal of Early Adolescence, 24(2), 85-112. https://doi.org/10.1177/0272431603262666

Brown, B. B., \& Klute, C. (2003). Friendships, cliques, and crowds. In G. R. Adams \& M. D. Berzonsky (Eds.), Blackwell handbook of adolescence (pp. 330-348). Malden, MA: Blackwell. https://doi.org/10.1002/9780470756607.ch16

Carter, E. W., Hughes, C., Guth, C. B., \& Copeland, S. R. (2005). Factors influencing social interaction among high school students with intellectual disabilities and their general education peers. American Journal on Mental Retardation, 110(5), 366-377.

Ciairano, S., Rabaglietti, E., Roggero, A., Bonino, S., \& Beyers, W. (2007). Patterns of adolescent friendships, psychological adjustment and antisocial behavior: The moderating role of family stress and friendship reciprocity. International Journal of Behavioral Development, 31 (6), 539-548. https://doi.org/10.1177/0165025407080573

Creswell, J. W. (2012). Educational research: Planning, conducting, and evaluating quantitative and qualitative research (4th ed.). Thousand Oaks, CA: Sage.

Dunn, J. (2004). Children's friendships: The beginnings of intimacy. Oxford: Blackwell Publishing.

Estell, D. B., Jones, M. H., Pearl, R., \& van Acker, R. (2009). Best friendships of students with and without learning disabilities across late elementary school. Council for Exceptional Children, 76(1), 110-124. https://doi.org/10.1177/001440290907600106

Fredricks, J., \& Eccles, J. (2006). Extracurricular involvement and adolescent adjustment: Impact of duration, number of activities, and breadth of participation. Applied Developmental Science, 10(3), 132-146. https://doi.org/10.1207/s1532480xads1003_3

Freeman, S. F. N., \& Kasari, C. (1998). Friendships in children with developmental disabilities. Early Education and Development, 9, 341-355. https://doi.org/10.1207/s15566935eed09 04_2

Frostad, P., \& Pijl, S. J. (2007). Does being friendly help in making friends? The relation between the social position and social skills of pupils with special needs in mainstream education. European Journal of Special Needs Education, 22, 15-30. https://doi.org/10.1080/08856250601082224

George, A. L., \& Duquette, C. (2006). The psychosocial experiences of a student with low vision. Journal of Visual Impairment \& Blindness, 100(3), 15-25. https://doi.org/10.1177/014548 2X0610000304

Gibbon, C. (2013). School-based extracurricular activity participation of high school youth with disabilities [Unpublished doctoral dissertation]. University of Illinois at Urbana-Champaign.

Gifford-Smith, M. E., \& Brownell, C. A. (2003). Childhood peer relationships: Social acceptance, friendships, and peer networks. Journal of School Psychology, 41, 235-284. https://doi.org/10.1016/S0022-4405(03)00048-7

Gillies, R. M. (2004). The effects of cooperative learning on junior high school students during small group learning. Learning and Instruction, 14(2), 197-213. https://doi.org/10.1016/S0959-4752(03)00068-9

Gordon, P. A., Feldman, D., \& Chiriboga, J. (2005). Helping children with disabilities develop and maintain friendships. Teacher Education and Special Education, 28(1), 1-9.

https://doi.org/10.1177/088840640502800101 
Gore, K. (2015). Attitudes between students with disabilities and typically developing students [Unpublished master's thesis]. Marshall University College of Education and Professional Development, USA.

Howie, L., Lukacs, S., Pastor, P., Reuben, C., \& Mendola, P. (2010). Participation in activities outside of school hours in relation to problem behavior and social skills in middle childhood. Journal of School Health, 80(3), 119-125. https://doi.org/10.1111/j.1746-1561.2009.00475.x

Kearney, A. C. (2009). Barriers to school inclusion: An investigation into the exclusion of disabled students from and within New Zealand schools [Doctoral dissertation]. Massey University, Palmerston North, New Zealand. http://hdl.handle.net/10179/876

Keller, M. (2004). A cross-cultural perspective on friendship research. International Society for the Study of Behavioural Development Newsletter. 46(2), 10-14.

Kenny, L., McNeela, A., \& Shevlin, M. (2003). Living and learning: The school experiences of some young people with disabilities. Dublin: NDA.

Koster, M., Pijl, S. J., Nakken, H., \& Houten, E. V. (2010). Social participation of students with special needs in regular primary education in the Netherlands. International Journal of Disability, Development and Education, (57)1, 59-75. https://doi.org/10.1080/10349 120903537905

Lifshitz, H., Hen, I., \& Weise, I. (2007). Self-concept, adjustment to blindness, and quality of friendship among adolescents with visual impairments. Journal of Visual Impairment and Blindness. 101(2), 96-107. https://doi.org/10.1177/0145482X0710100204

Macmillan, J. H., \& Schumacher, S. (2001). Research in education. New York: Harper Publishers.

Massoni, E. (2011). Positive effects of extra-curricular activities on students. ESSAI, 9(27), 84-87.

Matheson, C., Olsen, R. J., \& Weisner, T. (2007). A good friend is hard to find: Friendship among adolescents with disabilities. American Journal on Mental Retardation, 112(5), 319-329. https://doi.org/10.1352/0895-8017(2007)112[0319:AGFIHT]2.0.CO;2

Movahedi, A., Mojtahedi, H., \& Farazyani F. (2011). Differences in socialization between visually impaired student-athletes and non-athletes. Research in Developmental Disabilities, 32(1), 58-62. https://doi.org/10.1016/j.ridd.2010.08.013

Neary, M. K. (2010). Students with special needs and their interaction with peers during play [Unpublished doctoral dissertation]. University of New York College. https://digitalcommons.brockport.edu/ehd_theses/3

Parvin, S. (2015). Social inclusion of visually impaired students studying in a comprehensive secondary mainstream school in the south of England. International Journal of Scientific and Research Publications, 5(2), 1-5.

Pijl, S. J., \& Frostad, P. (2010). Peer acceptance and self-concept of students with disabilities in regular education. European Journal of Special Needs Education, (25)1, 93-105 https://doi.org/10.1080/08856250903450947

Pijl, S. J., \& Scheepstra, A. J. M. (1996). Being apart or being a part of the group: The positions of students with Down's syndrome in Dutch regular schools. European Journal of Special Needs Education, 11(3), 311-320.

Pijl, S. J., Frostad, P., \& Flem, A. (2008). The social position of pupils with special needs in regular schools. Scandinavian Journal of Educational Research, (52)4, 387-405. https://doi.org/10.1080/00313830802184558.

Robinson, S., \& Truscott, J. (2013). Belonging and connection of school students with disability issues paper. Sydney: Children with Disability Australia.

Rockson, G. N. (2014). Social relationship among students with visual impairment in two integrated senior high schools in Ghana [Unpublished Master's Thesis]. University of Education, Winneba, Ghana.

Roe, J. (2008). Social inclusion: Meeting the socio-emotional needs of children with vision needs. British Journal of Visual Impairment, 26(2), 147-158. https://doi.org/10. 1177/0264619607088277

Sacks, S. Z., \& Wolffe, K. E. (1998). Lifestyles of adolescents with visual impairments: An ethnographic analysis. Journal of Visual Impairment \& Blindness, 92, 7-17. https://doi.org/10.1177/0145482X9809200104

36 Consortia Academia Publishing (A partner of Network of Professional Researchers and Educators) 
Schaffer, H. R. (1996). Social development. Oxford, UK: Blackwell.

Schedlin, H., Lieberman, L. J., Houston-Wilson, C., \& Cruz, L. (2012). The academic learning time in physical education of children with visual impairments: An analysis of two students. Insight: Research and Practice in Visual Impairment and Blindness, 5(1), 11-22.

Scheepstra, A. J. M., Nakken, H., \& Pijl, S. J. (1999). Contacts with classmates: The social position of pupils with Down's syndrome in Dutch mainstream education. European Journal of Special Needs Education, 14, 212-220. https://doi.org/10.1080/0885625990140303.

Schneider, B. H. (2000). Friends and enemies: Peer relations in childhood. New York: Oxford Press Inc.

Shevlin, M., Kenny, M., \& McNeela, E. (2002). Curriculum access for pupils with disabilities: An Irish experience. Disability \& Society, 17(2), 159-169. https://doi.org/10.1080/09687590 120122314

Siperstein, G., Glick, G., \& Parker, R. (2009). Social inclusion of children with intellectual disabilities in a recreational setting. Intellectual \& Developmental Disabilities, 47(2), 97-107. https://doi.org/10.1352/1934-9556-47.2.97

Slavin, R. (2009). Educational psychology: Theory and practice (9th ed.). Upper Saddle River, New Jersey: Pearson Education, Inc.

Solish, A., Perry, A., \& Minnes, P. (2010). Participation of children with and without disabilities in social, recreational and leisure activities. Journal of Applied Research in Intellectual Disabilities, 23(3), 226-236. https://doi.org/10.1111/j.1468-3148.2009.00525.x

Tinto, V. (1975). Dropouts from higher education: A theoretical synthesis of recent research. Review of Educational Research, 45, 89-125. https://doi.org/10.3102/00346543045001089

Tipton, L. A. (2011). Friendship quality in adolescents with and without an intellectual disability [Unpublished maters' thesis]. University of California, Riverside.

Vanderstoep, S. W., \& Johnston, D. D. (2009). Research methods for everyday life: Blending qualitative and quantitative approaches. San Francisco: John Wiley \& Sons, Inc.

Wilkinson, I. A. G., Soter, A. O., \& Murphy, P. K. (2010). Developing a model of quality talk about literacy text. In M. G. McKeown \& L. Kucan (Eds.). Bringing reading research to life (pp. 142-169). New York: The Guilford Press.

Yin, R. K. (2003). Case study research: Design and methods (3rd ed.). Thousand Oaks, CA: Sage. 
